\title{
Théophile Gautier, Euvres complètes, section I, Romans, contes et nouvelles, t. 5, Le Roman de la momie, Spirite
}

\section{Lise Sabourin}

\section{(2) OpenEdition}

\section{Journals}

Édition électronique

URL : https://journals.openedition.org/studifrancesi/26601

DOI : 10.4000/studifrancesi.26601

ISSN : 2421-5856

Éditeur

Rosenberg \& Sellier

Édition imprimée

Date de publication : 1 avril 2007

Pagination : 201

ISSN : 0039-2944

\section{Référence électronique}

Lise Sabourin, «Théophile Gautier, E Euvres complètes, section I, Romans, contes et nouvelles, t. 5, Le Roman de la momie, Spirite », Studi Francesi [En ligne], 151 (LI | I) | 2007, mis en ligne le 30 novembre 2015, consulté le 23 novembre 2021. URL : http://journals.openedition.org/studifrancesi/26601 ; DOI : https://doi.org/10.4000/studifrancesi.26601

Ce document a été généré automatiquement le 23 novembre 2021.

\section{cc) (†) $\odot$}

Studi Francesi è distribuita con Licenza Creative Commons Attribuzione - Non commerciale - Non opere derivate 4.0 Internazionale. 


\title{
Théophile Gautier, Euvres complètes, section I, Romans, contes et nouvelles, t. 5, Le Roman de la momie, Spirite
}

\author{
Lise Sabourin
}

\section{RÉFÉRENCE}

THÉOPHILE GAUTIER, Euvres complètes, section I, Romans, contes et nouvelles, t. 5, Le Roman de la momie, Spirite, édition établie par Alain MONTANDON et Corinne SAMINADAYAR-PERRIN, Paris, Champion, 2003, «Textes de littérature moderne et contemporaine», n. 60, pp. 503.

1 Égypte hiéroglyphique, swedenborgienne Norvège: tels sont les horizons extrêmes des deux œuvres célèbres de Gautier que rassemble ce cinquième volume de la section romanesque de l'édition complète que réunit Alain Montandon, auteur des notes et variantes (établies sur le manuscrit conservé par Lovenjoul) de Spirite, tandis que Corinne Saminadayar-Perrin s'occupe du Roman de la momie dont elle propose un bref et utile glossaire égyptologique (pp. 269-270), outre les index des noms propres, de lieux, de personnages fictifs effectués par les éditeurs pour les deux romans. On lira avec vif intérêt les riches introductions (pp.11-70 et 273-316) de ces deux feuilletons parus initialement dans «Le Moniteur universel», respectivement en 1857 et 1865, avant leur publication chez Hachette et Charpentier. Le mirage égyptien auquel succombe toute la génération romantique est «une variante archéologique de la fascination orientale» que Gautier conçoit en «empire du Signe» comme le «berceau de l'Orient judéochrétien» (pp.21-22), sans pourtant que la saturation sémiotique offerte par les moindres détails de vêtements et d'objets puisse satisfaire le désir herméneutique, dans la droite ligne de la magie élitiste des hiéroglyphes antiques. Le «Turc d'Égypte» que se sent Gautier, toujours frustré de la réalisation du voyage en ce pays dont il importe la vision fantasmée sur les scènes parisiennes comme par ses contes fantastiques - on retiendra particulièrement la nouvelle de 1840, Le Pied de momie -, accomplit les motifs 
essentiels de son imaginaire personnel dans Le Roman de la momie: amour dans la mort par fusion des deux mondes que signale l'enchâssement du récit, statues animées du Pygmalion qui sommeille en son rêve de créateur, manipulation savante mais profondément symbolique du matériau historique et littéraire. Le «vertige de la représentation» (p.45) permet l'alliance ambiguë de l'humour et du merveilleux, l'entremêlement des structures populaires du conte de fées à l'ébauche d'un roman judiciaire, presque déjà policier. Si l'intrigue amoureuse n'exclut pourtant pas les intermittences du cœur exclusives d'une véritable apologie de la passion, si le majestueux déploiement de l'écriture peut donner la sensation d'une aporie narrative, la subtile relecture de l'Histoire sainte - hébraïque comme pharaonique - donne une portée mythique à cette «œuvre-mosaïque» (p.67) qui explique la fascination qu'elle exerce encore sur son lectorat, malgré l'accueil modeste initial. L'évocation des esprits a assuré le même succès à Spirite, immédiat cette fois, notamment chez les amateurs de tables tournantes, à la surprise même du - superstitieux pourtant - Gautier. Imprégné de connaissances sur le magnétisme, quoique incrédule, il ne pouvait qu'être pris par cette «écriture hantée» (p. 282) que les ouvrages liés au spiritisme mais aussi, plus profondément, la mystique de Swedenborg ont nourrie. Longfellow, Poe, Lytton, l'Armance de Stendhal et Le Vase d'or d'Hoffmann, lui-même inspiré du Mozart de La Flûte enchantée, alimentent cette sublimation des éléments autobiographiques qui investissent singulièrement Guy de Malivert et celle qui porta d'abord le nom éponyme élidé de Spirite. Là où le soleil écrasait l'amour égyptien, la neige à présent illumine l'obsession de la mort, rappelant de même «la néantisation des formes habituelles du monde» pour accéder à «la résurrection spirituelle» (p. 293). La vision de Paris en cimetière étincelant, la rêverie de course et de vol, le trajet initiatique de la mondanité au couvent, le relais esthétique assumé par la musique après la peinture sont autant d'images de ce «chant du cygne du poète Gautier qui, peut-être à l'écoute d'un Wagner qu'il découvre, sait l'indissoluble lien entre l'art, l'amour et la mort» (p. 315). Un volume donc qui réunit deux fort belles œuvres, présentées avec brio et sûreté. 